\title{
Communication Intervention in an Adolescent with Profound Cognitive Impairment and Autistic Features
}

\author{
Ilze Pansegrouw and Erna Alant \\ Department of Communication Pathology \\ University of Pretoria
}

\begin{abstract}
The service delivery model currently used with a large proportion of profoundly cognitively impaired (PCI) persons, results in the under-utilization of their potential and often contributes to social isolation. By providing communication and independence training the self-actualisation potential and the right to power and control, is recognised. This single case study describes the implementation of a communication intervention model with a PCI adolescent. His mother was trained in the use of picture symbol task analysis as well as positive reinforcement to promote change in the adolescent's communication skills and independence. Results indicated significant changes in the skills of both participants and highlighted the mother's need for support to meet the demands of change.
\end{abstract}

\section{OPSOMMING}

Die kenmerke van die diensleweringsmodel by 'n groot persentasie kognitief erg gestremde (KEG-) persone, resulteer dikwels in die onderbenutting van hul potensiaal en vir sommige in sosiale isolasie. Deur die voorsiening van kommunikasie. intervensie en onafhanklikheidsopleiding word in die selfuerwesenlikingspotensiaal van die KEG-persoon voorsien en word sy/haar selfhandhawingsregte erken. Hierdie enkelgevalstudie beskryf' $n$ kommunikasie-intervensiemodel wat by 'n KEGadolessent toegepas is. Die moeder van die adolessent is in diegebruik van prentsimbooltaakanalises en positiewe versterking opgelei met die oog op verandering by die kommunikasievaardighede en onafhanklikheid van die adolessent. Resultate het betekenisvolle verandering in die doelstellings van die studie aangetoon en die ondersteuningsbehoeftes van die moeder ten opsigte van die eise wat verandering meebring, is beklemtoon.

KEY WORDS: profound cognitive impairment (PCI), communication intervention, independence training.

\section{INTRODUCTION}

Due to limited provision of services and facilities the needs of a significant proportion of cognitively impaired persons (CIP) are not being met (Alant \& Emmett, 1995). Services such as speech therapy are often not accessible due to beliefs that poor progress in therapy indicates that these persons do not benefit from such therapy (Calculator, 1988a). Consequently, a large percentage of CIP persons reside in segregated "special-care" units where total physical care is the only form of service provided (Lea, 1990). In addition, parents of those who reside at home report a lack of formal an informal societal assistance such as respite care to relieve caregiver stress (Singer \& Irvin, 1991).

The results of limited services to both parents and CIP persons are far-reaching. It is known that the clinical picture of a large proportion of these persons relates to the nature of service delivery and the intervention approach (Lea, 1990). The intervention approach to profound cognitive impaired (PCI) persons (I.Q. 20 and less) is clearly demonstrated in the categorisation of these persons as "untrainable" (Grover, 1990). The term "untrainable" implies that the person does not have the ability to benefit from education or training and is therefore dependent on total physical care (Koördineringskomitee: Jaar van Gestremde Persone, 1987). These persons represent approximately $1 \%-2 \%$ of the cognitively handicapped population (Subcommittee on Mental Retardation, 1987a). Clinical features include the description of a high percentage of self injurious and socially unacceptable behaviour, as well as low motivation relating to the development of independence skills (Sailor \& Guess, 1983). Language and communication impairment represent the most pervasive problem of the majority of PCI persons and have been linked to the high incidence of severe behavioural problems in this group of people (Durandt, 1990; Yoder \& Villarruel, 1988). Due to frequent impairment in motor abilities, functional speech skills are often severely limited (Sailor \& Guess, 1983).

Apart from the individual's inability to communicate, however, the inability to respond to the interaction attempts of primary caregivers often results in the gradual reduction of primary caregiver attempts to interact with the impaired person. This leads to low caregiver expectations regarding communication from the impaired person, reduced opportunities to support the development of language, communication and social skills and results in severe difficulty 
in forming or participating in even the most basic social relationships (Kirchener, 1991). Primary caregivers often compensate and adapt to the impaired person in a way that contributes to the development of "learned helplessness" (Yoder \& Villarruel, 1988). Learned helplessness is seen in the anticipation of all needs of the impaired person and results in low demands for communication and low participation in domestic activities and household routines. These features result in reduced social environmental integration of the impaired person.

One of the most important indicators of the quality of life, is the extent of a person's social integration (Haring, 1991). From the above discussion the following principles of communication intervention can be formulated. These principles provide important criteria for successful intervention with PCI persons:

- Quality of life is determined by the extent to which the person is socially integrated in his daily environment. Independence skills provide opportunities for active par- ticipation in daily activities and routines within the en. vironment (Haring, 1991).

- The quantity and quality of communication interaction between the PCI person and the environment, relate closely to the communication skills of the impaired per. son. The PCI person cannot be viewed apart from his/ her daily environment; this person is viewed as one component of the environment in which he lives and spends most of his time (Gottlieb, 1988).

- The above implies that the term "client" comprises both the impaired person and his environment.

In the following, the application of the aforementioned principles to develop a model for communication intervention with a PCI person, is discussed.

\section{PROPOSED MODEL FOR INTERVENTION}

In this study a communication. intervention model was developed to address the principles and important criteria

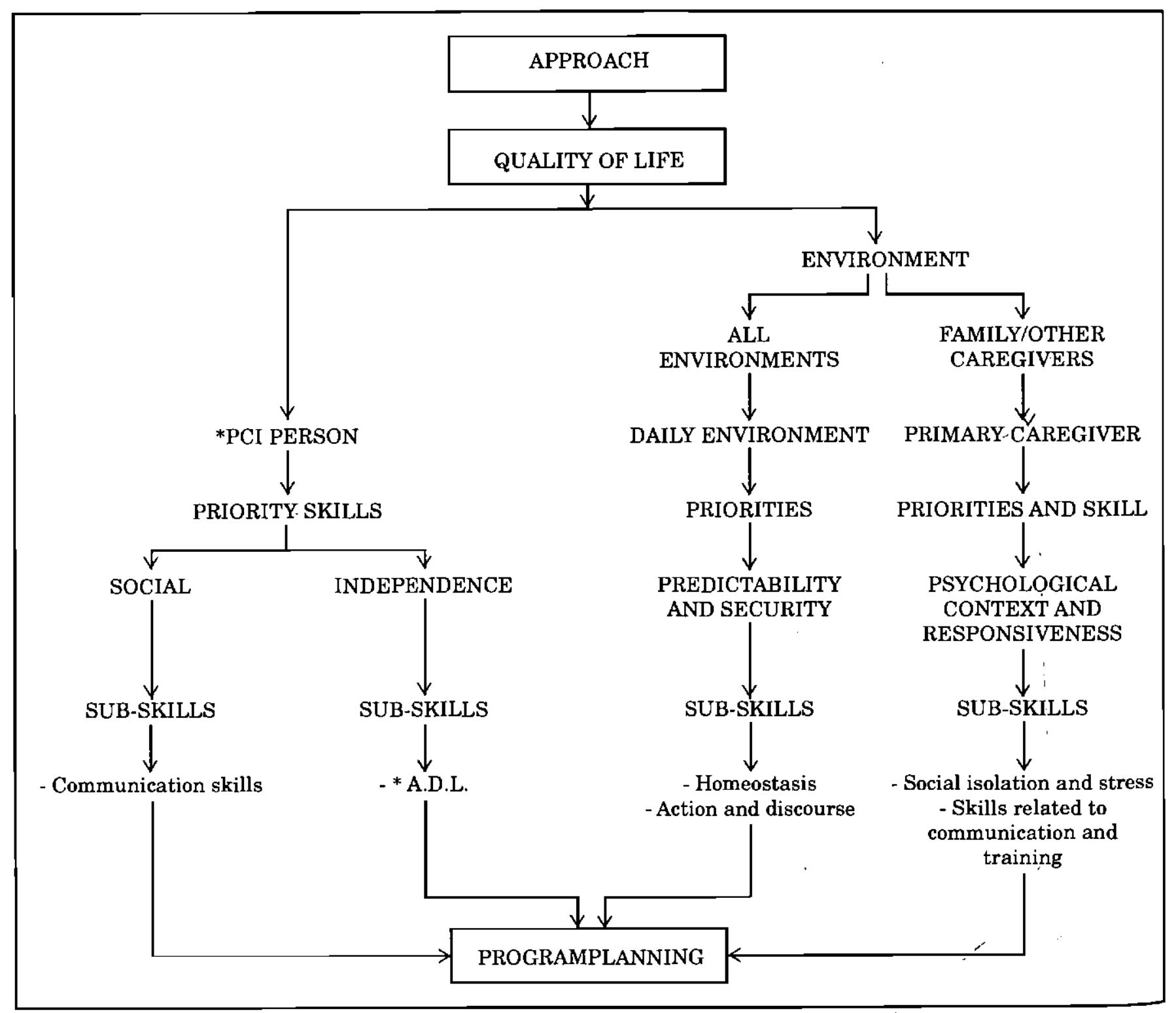

KEY: * A.D.L. = Activities of Daily Life

* PCI PERSON = Profound cognitive impaired person

FIGURE 1: Client approach: Communication intervention model 
for intervention with $\mathrm{PCI}$ persons. This model is presented in Figure 1. Figure 1 provides criteria to identify the daily environment and the primary caregiver as well as priority skills that were identified for the client.

Central to this model is the concept of quality of life, thus the facilitation of social interaction and the development of independence for active participation within this context. The functioning of the person is the product of interaction between the person and the environment (Ehren \& Lenz, 1989). Figure 1 demonstrates a clear distinction between the family or other caregivers and the primary caregiver as well as between the daily environment (where the person spends most of his time) and other environments which he might visit on occasion.

The primary caregiver is identified as the person with whom the PCI person has a high frequency of contact, who elicits a high frequency of communication initiations and responses from the person and with whom there exists a strong affective bond (Owens \& Rogerson, 1988). For obvious reasons, this would be the most important starting point in intervention.

Figure 1 demonstrates that for the PCI person, social integration, i.e., the acquisition of communication skills and becoming independent within this context, is a high priority. The extent of the person's ability to develop stable social relationships in order to achieve active social integration within the daily environment, provides and indication of the needs for support of the person. The development and maintenance of active, social integration is dependent on functional communication skills which are prerequisites for the development and maintenance of social integration (Rustin \& Kuhr, 1989). It follows that PCI persons, who often do not develop functional speech production skills and who do not have access to AAC (Augmentative and Alternative Communication) methods, will experience severe difficulty in forming and maintaining social relationships with others in the environment if support in the form of communication intervention is not provided.

Similarly, skills related to Activities of Daily Living (activities occurring frequently and that are essential for the maintenance of hygiene and order within the daily environment) determine the level of independence within the daily environment (Eshilian, Haney \& Falvey, 1989).

Homeostasis (see Figure 1) within the daily environment refers to environmental attempts which aim at creating predictability and security to maintain the existing structure and order of the environment (Lund, 1986). Radical change of environmental homeostasis (such as change as a result of intervention) poses a threat to environmental predictability and security and if not managed sensitively, can result in resistance to change (Conti-Ramsden, 1985). Action and discourse routines on the other hand, refer to frequently occurring, highly predictable action or conversation events that, once they begin, unfold in the same manner each time they occur (Lund, 1986). Action routines thus refer to an event such as ball play where the action forms the main activity between the persons involved while discourse routines refer to an event such as greeting where the conversation forms the main activity between the persons involved. Routines play an important role in the maintenance of homeostasis and are equally important to the development of social and communication skills (Rowland \& Stremel-Campbell, 1987).

When looking at the primary caregiver, it can be seen in Figure 1 that the psychological context, as well as skills related to caregiver responsiveness training are deemed priorities in this intervention model. Socially constructed factors and processes are often the cause for the primary caregiver's social isolation and stress (Lea, 1990). Social isolation and associated stressors are found in the presence of stigmatisation and limitèd support services (Lea, 1990; Helm \& Kozloff, 1986). Limited knowledge and skill can, amongst others, result in counter productive interaction patterns such as limited primary caregiver responsiveness (Calculator, 1988b). Primary caregiver responsiveness is acknowledged as a key factor in the development of interaction and communication for the PCI person (Girolametto, Greenberg \& Manolson, 1986). In considering responsiveness, the skills of the primary caregiver in terms of how much communication is expected of the PCI person and whether utterances directed at the person are interaction and discourse orientated, are taken into account (Siegel-Causey \& Downing, 1987).

It is against this background that a study was conducted to explore the applicability of the above model of communication intervention for a PCI person adolescent with autistic features. Specific priority skills and other skill areas were identified according to the model described in Figure 1.

\section{METHODOLOGY}

\section{AIMS OF THE STUDY}

The main aim of the study was to develop a communication intervention programme for a PCI person by means of identified priority skills.

The sub-aims were three-fold: Firstly a pilot study was conducted to identify the needs of the subject and his mother relating to priority skills, to conduct an intervention trial and to develop relevant intervention materials. The second sub-aim was to implement the programme that was developed by describing the communication of the mother and her skills at training the subject and to describe the communication and independence at performing action routines, of the subject. The third sub-aim was to describe the results of identified priority skills of the subject and his mother during the six week intervention period as well as the effect of the withdrawal of intervention during week six.

\section{RESEARCH DESIGN}

A quasi-experimental single case study with a multiple baseline (ABA) design with withdrawal was selected for use in this study. The multiple baseline design for the measurement of change in behaviour patterns is well suited to execute ABA comparisons (Kearns, 1986). The mother-subject dyad was used whereby the behaviours of both were recorded. The research design is presented in Table 1.

It is known that motivation plays a significant role in the learning process and that repeated failure most often results in a decrease in motivation as well as task avoidance (Haney \& Falvey, 1989). The "feed the cat" routine was completely unfamiliar to the subject. Because both the "make the bed" and "set the table" routines were not completely unfamiliar to the subject it was decided to introduce these before the "feed the cat" routine to make sure that success was highly likely with the first two routines. A withdrawal period could establish whether changes in the subject and the mother could be attributed to the intervention. The action routines which were introduced one after 
the other, were performed for the whole intervention period (not during withdrawal) because it is known that PCI persons forget learning material which is not reinforced regularly and on a daily basis (Brown, 1983).

\section{$S U B J E C T$}

For the study, a fifteen (15) year old PCI subject was selected from nine possible candidates at a school for autistic children in Pretoria. The subject received individual speech therapy aimed at the development of speech production for the first six years in school. The production and imitation of a few single words are reported between the ages of two and four with a gradual decrease in vocalisations since then. The subject was introduced to $\mathrm{AAC}$ at the age of eleven years. During the initial training stages, photographs of highly motivational objects and actions for the subject were used and after six months, Makaton picture symbols (1985), were introduced. Table 2 provides the psychiatric diagnosis of the subject, formal assessment results as well as a description of the communication and independence skills of the subject.

\section{MOTHER}

The mother, who is the primary caregiver, took very good care of the subject. She has an honours degree in Biochemistry but was not employed at the time of the study. Other family members included the father and an older non-impaired brother.

\section{PILOT STUDY}

The pilot study consisted of two phases. Phase one aimed at needs identification and the gathering of information on the pre-intervention state of priority skills of the subject and his mother. The information gathered during phase one, was utilised to conduct phase two of the pilot study. Phase two was aimed at an intervention trial with the class teacher of the subject as well as the development of an instrument to measure change during intervention.

\section{Phase 1: Needs identified by the mother}

During phase one the mother expressed the view that increased independence in the area of A.D.L. was the subject's main need and that she would like to see the subject become independent in setting the table at home (an action routine which he has been exposed to at school), making his bed (inconsistent attempts at this had been made previously by mother) and feed the cat (to which he had no previous exposure). The mother expressed limited knowl. edge and self-confidence in training the subject. During video-recordings of two domestic action routines (loading the washing machine and unpacking the dishwasher), the subject indicated a strong need for positive reinforcement responses from his mother when he succeeded in certain parts of action routines. Significant features of the mother's communication included the introduction and repetition of a limited amount of conversational topics with the subject, a high percentage of commands and low percentage of responsive utterances/actions. It was noted that due to the under-utilisation by the subject of his AAC system (refer to discussion of PCI subject), his communication intentions were often not understood by his mother.

At the end of phase one, two priority skills, namely communication skills and skills at training the subject, were selected for the mother. For the subject, communication skills and independence at performing those action routines that were selected by his mother (setting the table, making the bed and feeding the cat), were identified.

\section{Phase 2: Development of action routines and prelimi- nary testing}

During phase two a concrete positive reinforcement sticker chart (commercially available white, square, peeloff stickers) as well as three preliminary picture symbol task analysis charts were developed for each one of the three action routines that were identified by the mother. A task analysis is the "breaking down" (analysis) of a learning task into smaller, more manageable steps with the aim of introducing the task as a "chain" of related steps. This task analysis method is an acknowledged strategy in domestic independence training of cognitively impaired persons (Sailor \& Guess, 1983).

Although three preliminary picture symbol task analysis charts were developed, only "set the table" was used in the intervention trial. The subject's teacher was asked to participate as "primary caregiver" in the trial with the aim of testing the usefulness and appropriateness of intervention materials. The teacher was trained to use the task analysis and positive reinforcement chart and the trial performance of "set the table" action routine was video recorded. For the purpose of this study only the primary caregiver

TABLE 1: Research design

\begin{tabular}{|l|c|c|c|c|c|c|c|c|}
\hline WEEK & $\begin{array}{c}0 \\
13 / 7\end{array}$ & $\begin{array}{c}1 \\
13 / 7-20 / 7\end{array}$ & $\begin{array}{c}2 \\
20 / 7-27 / 7\end{array}$ & $\begin{array}{c}3 \\
27 / 7-3 / 8\end{array}$ & $\begin{array}{c}4 \\
3 / 8-10 / 8\end{array}$ & $\begin{array}{c}5 \\
10 / 8-17 / 8\end{array}$ & $\begin{array}{c}6 \\
17 / 8-22 / 8\end{array}$ & $\begin{array}{c}6 \\
22 / 8\end{array}$ \\
\hline SET THE TABLE & $\mathrm{A}$ & $\begin{array}{c}\mathrm{B} 1 \\
\mathrm{~B}\end{array}$ & $\begin{array}{c}\mathrm{B} 1 \\
\mathrm{~B}\end{array}$ & $\mathrm{~B} 1$ & $\mathrm{~B} 1$ & $\mathrm{~A} 1$ & $\mathrm{~A} 1$ & $\mathrm{~B}$ \\
\hline MAKE THE BED & $\mathrm{A}$ & $\begin{array}{c}\mathrm{B} 1 \\
\mathrm{~B}\end{array}$ & $\begin{array}{c}\mathrm{B} 1 \\
\mathrm{~B}\end{array}$ & $\mathrm{~B} 1$ & $\mathrm{~B} 1$ & $\mathrm{~A} 1$ & $\mathrm{~A} 1$ & $\mathrm{~B}$ \\
\hline FEED THE CAT & $\mathrm{A}$ & & $\mathrm{B} 1$ & $\begin{array}{c}\mathrm{B} 1 \\
\mathrm{~B}\end{array}$ & $\mathrm{~B} 1$ & $\mathrm{~A} 1$ & $\mathrm{~A} 1$ & $\mathrm{~B}$ \\
\hline
\end{tabular}

KEY: $\quad A=$ Baseline measurements

$\mathrm{B}=$ Measurements

B1 = Performance of action routines

A1 $=$ Withdrawal 
(refer to discussion on proposed model for intervention) of the subject was selected and the class teacher was only involved in the intervention trial.

\section{MEASUREMENT INSTRUMENT}

The measurement instrument was developed to record and describe information on the identified priority skills of the subject and his mother. (See introductory paragraphs for the discussion and relevance of the selected priority skills). Skills selected for measurement were identified by analysing each priority skill into sub-skills. The selected behaviours for observation were supplemented by observing video-recordings of week 0 . Sub-skills were either marked + (positive) or - (negative). Positive behaviours (+) were those where an increase indicated a positive change and negative (-) behaviours were those where an increase indicated a negative change.

TABLE 2: Subject: Psychiatric diagnosis, formal assessment results, communication and independence skills

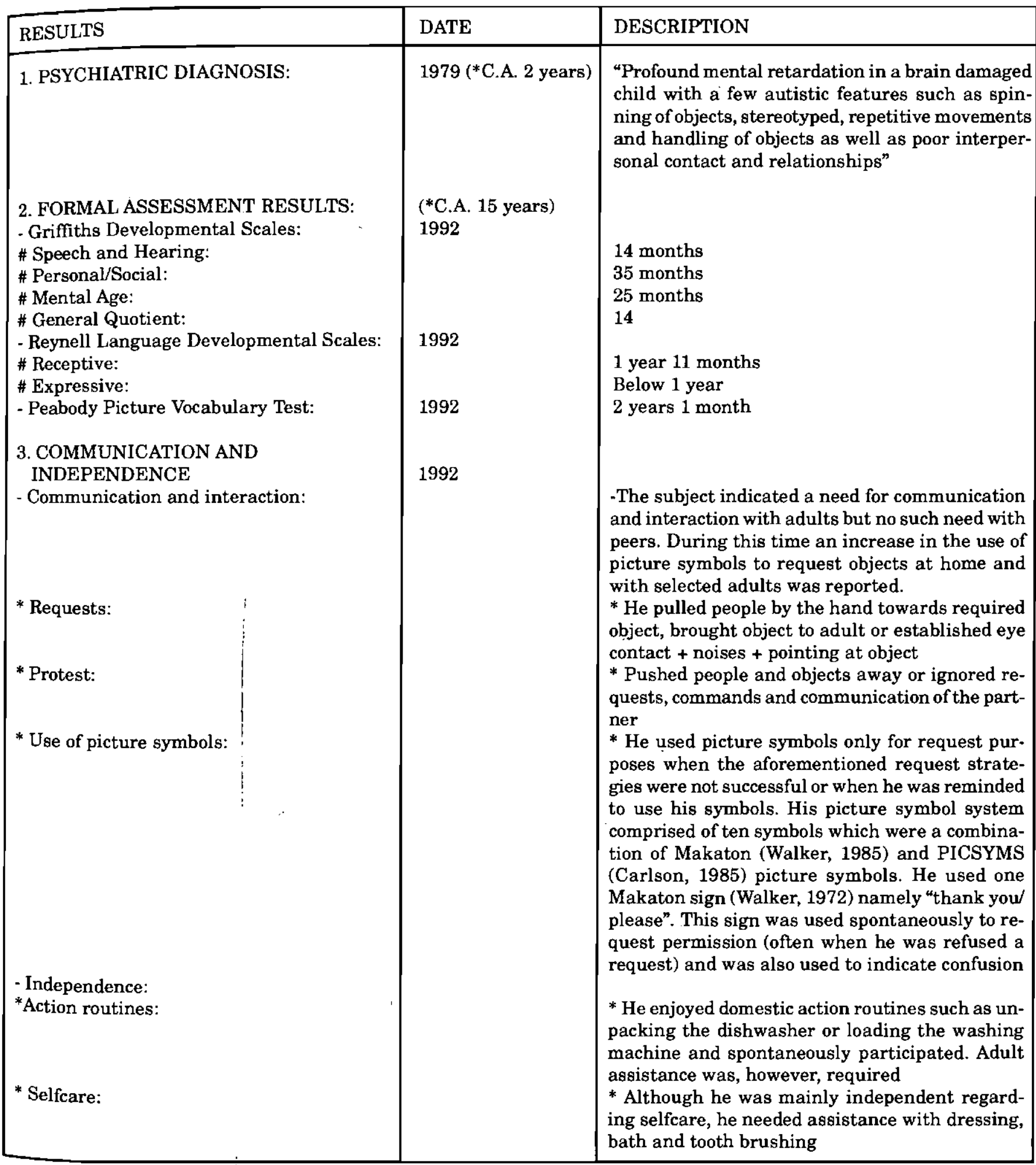

KEY: * C.A. = Chronological age 
Appendix 1 provides the grouping of sub-skills of priority skills of the subject and his mother. Appendix 2 provides the grid which was used to record and analyse data regarding sub-skills of the mother's skills at training the subject. The sub-skills of the other three priority skills, i.e. sub-skills of the mother's communication skills and the subskills of the independence and communication skills of the subject, were recorded onto three other grids.

\section{RESULTS OF PRELIMINARY TEST}

Results of phase two not only indicated the effectiveness of procedures but also highlighted the need for minor changes. A "theme symbol" was added as well as a separate column on the task analysis chart for positive reinforcement stickers. The mother suggested the use of "Spot", "Donald Duck" and "Ladybug” commercially available stick-

TABLE 3: Picture symbol task analysis of action routines

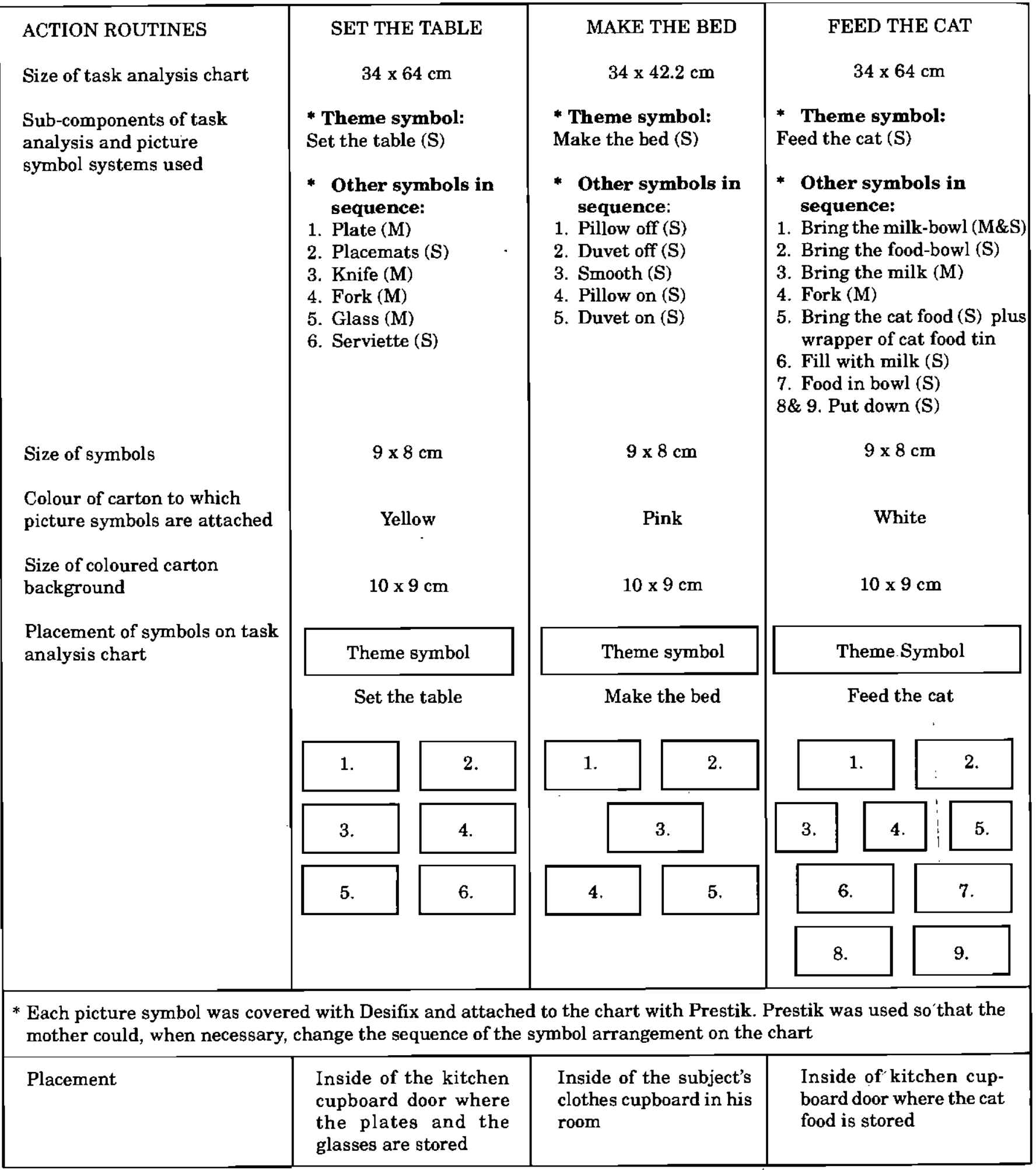

Key: $(\mathrm{M})=$ Makaton

(S) = Self-developed symbols 
ers because the subject was familiar with these icons from watching animated videos and indicated enjoyment whenever he saw them. The mother of the subject was consulted regarding the size and placement inside the family home of the task analysis charts. These suggestions were combined with the results of the trial intervention to determine the features and application of training materials used in the main study.

\section{THE MAIN STUDY}

\section{Training materials}

Table 3 provides information on the picture symbol task analysis charts of the three action routines and Table 4 provides the features and placement of positive reinforcement stickers that were used as training material for the adolescent. More detail on the development of these materials can be obtained in Pansegrouw (1994).

The implementation of action routines were video recorded in the family's home during time slots when these activities would normally take place. "Set the table" action routines were recorded at 19:00, "make the bed" at 07:00 and "feed the cat" at 10:30.

\section{PROCEDURES}

\section{Data collection}

Baseline video recordings (A-phase; see Table 1) of the three action routines were done at the family home on the first day of the experiment (week 0 ). The mother was asked to introduce the subject to the three selected action routines one after the other. For the baseline recordings the mother received no training or task analysis charts. After the baseline recordings, on the same day, the mother received the task analysis chart, instructions for use and relevant training for the "set the table" action routine.
Measurement recordings (B-phase; see Table 1) were done at the same time in which these action routines would normally take place in the family's home. The first measurement video recording was made of the "set the table" routine seven days after the introduction thereof. On the same day the task analysis chart, instructions for use and training for the "make the bed" action routine was introduced to the mother. She received instructions to continue the "set the table" action routine during the following week. Seven days after the "make the bed" action routine was introduced, this action routine was measured for the first time and the "set the table" routine measured for the second time. On the same day the "feed the cat" action routine was introduced to the mother. She received instructions to continue with the "set the table" and "make the bed" action routines in the following week. After seven days, the "feed the cat" action routine was measured for the first time and the "make the bed" routine for the second time. The mother received instructions to continue with the performing of the three action routines for another seven days and then to withdraw intervention for two weeks. On the last day of the two week withdrawal period, the third measurements of the "set the table" and "make the bed" as well as the second measurement of "feed the cat" routine were done.

\section{Training procedures and instructions}

Training procedures included detailed instructions to the mother on how to perform and train action routines once a day. Typed, as well as verbal instructions, specified utterances to be used an non-verbal guidance (such as pointing, gesture, physical guidance) to attract, direct and maintain the attention of the adolescent during the action routine. Instructions to pause regularly in order to create opportunity for the subject to initiate communication and to demonstrate independence development, were given to the mother. She was also instructed to respond to all communication attempts and other noise/sounds that the subject

TABLE 4 : Concrete positive reinforcement

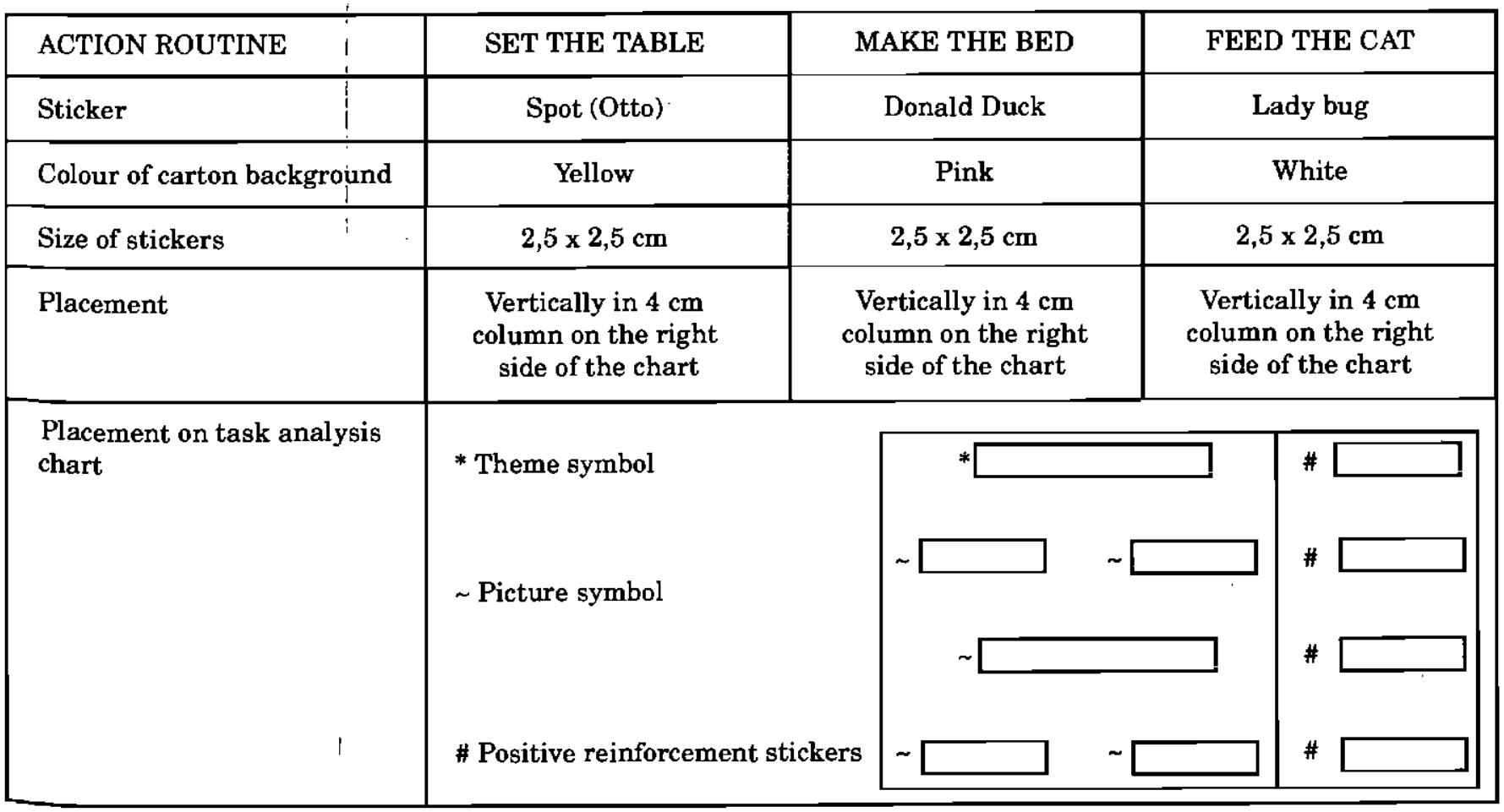


produced during the performance of action routines.

Instructions for the performance of the "set the table" action routine were as follows:

- Mother was asked to place four each of plates, knives, forks, glasses, placemats and serviettes alongside each other in the cupboard where these objects are kept. She was asked to show the subject where the objects were placed.

- Mother said "S. it is time now to set the table; we are going to eat."

- Mother directed/physically cued subject to the task analysis chart.

- Mother pointed to the theme symbol and said: "Look, it is time now to set the table" (she directed the subject's attention to the theme symbol.)

- Mother looked at the subject, pointed to the theme symbol and said, "S. please get the plates from the cupboard."

- Mother directed the subject's attention to the plate picture symbol and pointed to the cupboard where the plates were kept.

- If he understood the instruction and performed the action without any trouble, mother said: "Put a plate on the table for dad, put a plate down for A., a plate for me and a plate for yourself."

- Mother was encouraged to compliment verbal instructions with gesture and facial expression.

- Should the subject experience difficulty with any instruction, mother repeated the instruction and physically cued him through the action. After all the plates were placed on the table, the other utensils (forks, knives, placemats, glasses and serviettes) were placed on the table by using the same procedures and instructions.

Instructions for the use of positive reinforcement were as follows:

After the performance of a correct action by the subject the mother was requested to do or say the following:

- "Very good!" (positive reinforcement: verbal);

- smile (positive reinforcement: smile);

- squeeze his hand/shoulder (positive reinforcement: physical) and

- to place a sticker (positive reinforcement: concrete) in the left upper corner of the appropriate picture symbol.

- After the attachment of the sticker, mother pointed to the sticker and repeated: "Very good!"

\section{Data analysis and statistical processing}

Verbatim transcriptions of video material of the interaction between the mother and subject during action routines were done. Due to the fact that the subject did not communicate verbally, his communication was described by recording occurrences of pointing, smiles, gesture, eye contact as well as communicative sounds and noises on the relevant recording sheets. (Appendix 2 provides an example of a recording grid). Recording was done by counting each occurrence of a sub-skill on the transcriptions. Tallies were recorded onto the four different grids (see Appendix 2). The Friedman Variance Analysis (Hollander $\&$ Wolfe, 1973) was applied to the data to indicate P-val- ues (significance of change) of the sub-skills of the prior. ity skills over the six week intervention period. The P. value indicates significance of change of the difference between week 0 and any other measurement between week 0 and week 6 . Raw scores were processed to tallies per minute and the average percentage change in relation to week 0 (baseline), calculated. The percentage change refers to the percentage change in relation to week 0 . For equivalence of action routines, interpolation was done to determine percentage change for week three of "set the table". In this way the change in priority skills for week 2 for both "set the table" and "make the bed" as well as week 3 and 6 (in relation to week 0 ) for all action routines, could be presented. At the comparison of the sub-skills for all action routines only the percentage change at weeks 3 and 6 are presented. This was done because the "feed the cat" action routine was only introduced in week 2 and measured one week later (see Table 1). Through these procedures, changes in sub-skills of priority skills at weeks 0 , 3 and 6 could be calculated for all action routines.

\section{RESULTS AND DISCUSSION}

The results of intervention, i.e. a description of identified priority skills of the subject and his mother during the six week intervention period as well as the effect of withdrawal of intervention during week six, follows.

Figure 2 represents the overall results of the percentage change of the two priority skills of the mother (communication skills and skills at training the subject) and the two priority skills of the subject (communication skills and independence at performing action routines) in weeks three and six.

From Figure 2 it is evident that positive changes were seen in the results of the priority skills of the subjects. The subject benefitted from and developed new skills during the six week intervention period. At the time of the study, the chronological age of the subject was fifteen. $\mathrm{He}$ then was found to have a M.A. (Mental Age) of 25 months

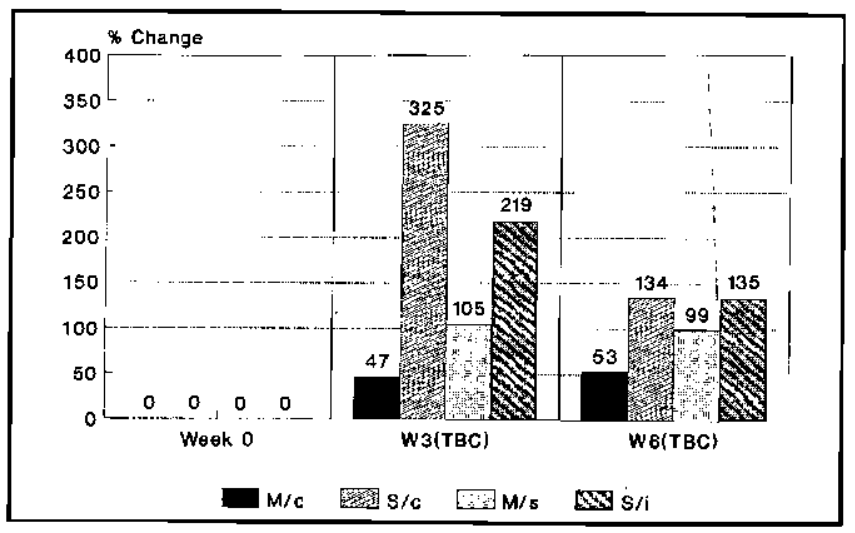

Key:

$(\mathrm{TBC})=$ Set the table; $\mathrm{B}=$ make the bed; $\mathrm{C}+$ Weed the cat

$\mathrm{M} / \mathrm{c} \quad=$ Mother: communication skills

$\mathrm{S} / \mathrm{c} \quad=$ Subject: communication skills,

$\mathrm{M} / \mathrm{s}=$ Mother: skills at training the subject

$\mathrm{S} / \mathrm{i}=$ Subject: independence at performing action routines

FIGURE 2: Change of priority skills at weeks three and six 
and a G.Q. (General Quotient) of 14 . According to existing psychometric categorisation the subject would be "untrainable" which implies an inability to benefit from education/training and consequently being dependent upon physical care (Grover, 1990; Koördineringskomitee: Jaar van Gestremde Persone, 1987). Results of this study support the view that clinical features are dynamic and often reflect the extent and nature of the service delivery model (Lea, 1990). Physical care as the only form of service delivery to the subject, would most certainly have resulted in the under-utilisation of potential.

\section{THE SUBJECT'S COMMUNICATION AND INDE- PENDENCE SKILLS}

When looking at Figures 2, 3 and 4 a significant difference in results between weeks nil to three (during intervention) and weeks nil to six (after intervention withdrawal) in the priority skills of the subject, is seen. Results in Figure 3 indicate that in weeks nil to six independence skills either increased or remained nearly the same. From the same figure it can also be seen that communication skills (apart from picture symbol communication which he used to indicate that he wanted to terminate routines) decreased from weeks nil to six. From these results it seems that the subject did not lose/forget skills during intervention withdrawal but instead presented poor motivation and unwillingness to co-operate. It is known that regular, consistent practice of skills with a familiar person in the environment, as well as the provision of external structure to facilitate productive functioning are important requirements for intervention success with PCI persons (Siegel-Causey \& Downing, 1987).

During the withdrawal period provision of external structure and regular performance of action routines decreased significantly. For this reason it becomes clear that so called generalisation problems often reflect a situation where behaviour has generalised but where reinforcement

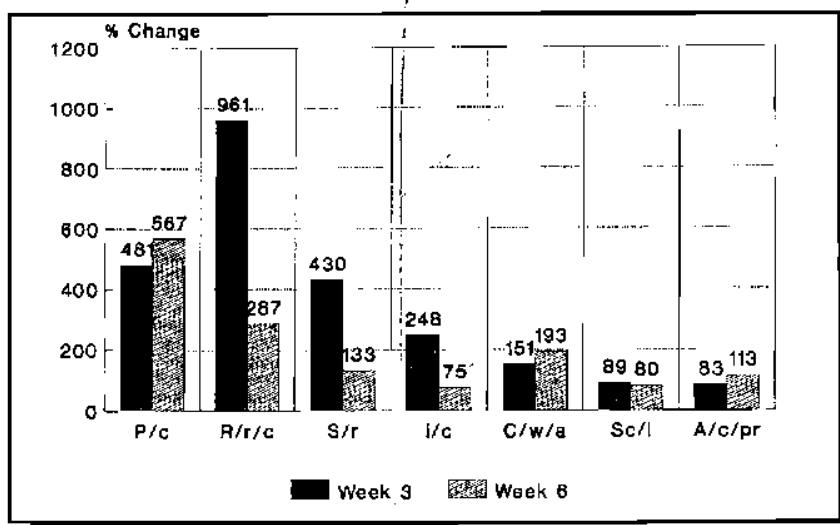

Key:

$\mathrm{P} / \mathrm{c}=$ Picture symbol communication; $\mathrm{R} / \mathrm{r} / \mathrm{c}=$ Requests for recognition/confirmation; $\mathrm{S} / \mathrm{r}=$ Smiles for recognition; I/c = Intentional communication; $\mathrm{C} / \mathrm{w} /$ a $/=$ Performs commands without assistance from mother; Sc/i = Performs sub-components of action routines independent/without command from mother $; \mathrm{A} / \mathrm{c} / \mathrm{pr}=$ Anticipates concrete positive reinforcement

FIGURE 3: Subject: Selected sub-skills of communication skills and independence (all action routines) for the regular use of the behaviour, was insufficient (Johnson \& Koegel, 1982). Increases were seen in the results of the subject's requests for and smiles for recognition, as well as anticipation of concrete positive reinforcement. These results indicate that the subject's related needs were addressed by providing his mother with positive reinforcement training. It also suggests that the often described clinical feature of poor inner motivation of the PCI person to develop skills that would decrease dependence of persons in the environment, could be changed by providing motivation (positive reinforcement) as the first step in the learning process (Sailor \& Guess, 1983; Haney \& Falvey, 1989).

When looking at increases in the results of the communication skills of the subject (Figures 2, 3 and 4), it seems that the provision of picture symbol task analysis charts to introduce action routines, provided the context in which communication between the mother and the subject was encouraged through the provision of common, specific themes that facilitated interaction (Lund, 1986; Rowland \& Stremel-Campbell, 1987). Task analysis charts provided the subject with the opportunity to acquire new information slowly and to be provided with small amounts of information at a time required by most PCI persons during the introduction of learning tasks (Wilson, 1981).

\section{THE MOTHER'S PRIORITY SKILLS}

Figure 2 results represent increases between weeks nil to three and weeks nil to six in the priority skills of the mother. When comparing overall percentage increases, the increases in the priority skills of the mother were not as high as those of the subject. However, Figure 5 results, which represent high increases in both positive responses (identification, recognition and positive response to communication attempts of the subject) and concrete and verbal positive reinforcement, are significant.

Increases in positive responses and concrete and verbal positive reinforcement suggest that the training of the mother in the use of positive reinforcement was not only effective, but most likely contributed to increases in positive responses. The use of positive responses were not directly trained and could therefore possibly be viewed as a "spill-over" effect of positive reinforcement training. The significance of these results is underlined by the view that for the PCI person, partner responsiveness is known to encourage and facilitate interest in and willingness to participate in communication interaction (Girolametto et al., 1986).

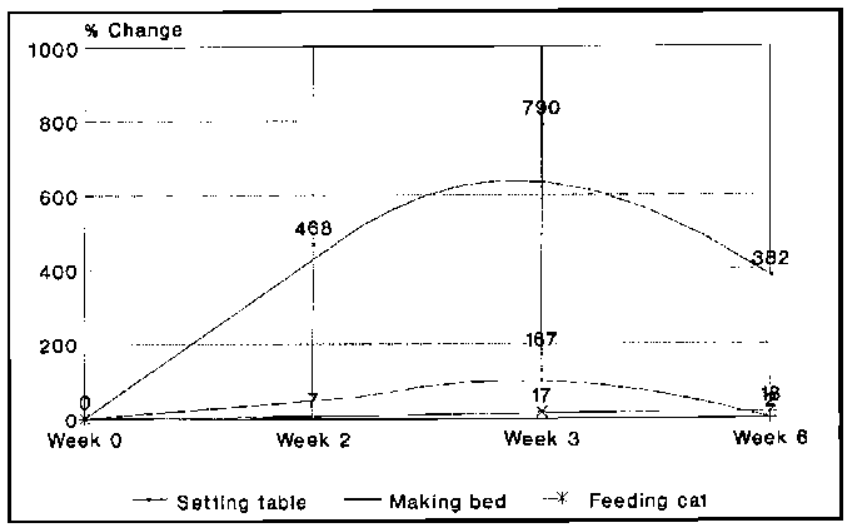

FIGURE 4: Subject: communication skills trends 


\section{COMPARISON IN PRIORITY SKILLS : THE SUB- JECT AND THE MOTHER}

Significantly fewer overall increases in the priority skills of the mother, when compared to those of the subject, are seen in Figure 2. When adding the overall increases of the mother as presented in Figure $2(47 \%$ in weeks $0-3$ and $53 \%$ in weeks $0-6$ for communication skills and $105 \%$ in weeks $0-3$ and $99 \%$ in weeks $0-6$ for skills at training the subject), only a slight change (50\%) in mother's communication behaviour over the six week intervention period is seen. The slower tempo of change of the mother could be viewed against the backdrop of the "set" of table management strategies that have developed over years in order to meet and cope with the daily demands of the PCI person. Due to limitation in formal and informal societal assistance, families develop rigid/stable strategies which are instrumental in maintaining environmental predictability, security and familiarity (see discussion of homeostasis under proposed intervention model). During the study a few of the family's rules and strategies were observed and mentioned by the mother. It follows that despite mother's willingness to participate in the study and to implement intervention strategies, demands to change management and coping strategies that have provided security and predictability over years, would require a much longer period of professional and social support.

However, when looking at Figure 2, it is seen that the communication skill of the mother was the only priority skill that showed an increase in week nil to six (after intervention withdrawal). A possible explanation for this could be found when comparing Figure 4, 5 and 6 .

In Figure 4 the highest scores during weeks nil to three for the three selected action routines are seen for "set the table" (in which the subject had most prior intervention experience), second highest for "make the bed" (less prior experience than setting table) and third highest for "feed the cat" (least prior experience). After withdrawal of in-

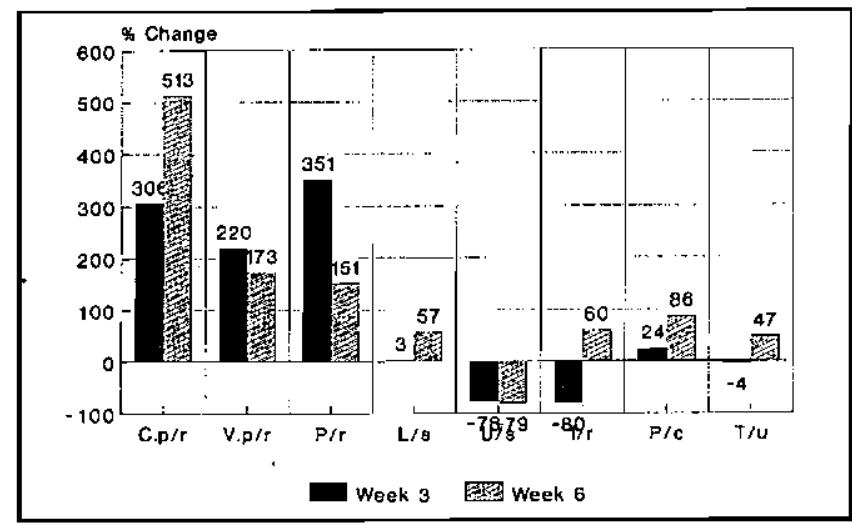

Key:

C.p/r = Concrete positive reinforcement; V.p/r = Verbal positive reinforcement; $\mathrm{P} / \mathrm{r}$ - Positive responses to communication of subject; $\mathrm{L} / \mathrm{s}=$ Looks at subject; U/s = Uses symbols; $\mathbf{I} / \mathbf{r}=$ Ignore responses to communication of subject; $\mathrm{P} / \mathrm{c}=$ Physical contact; $\mathrm{T} / \mathrm{u}=$ Total utterances

FIGURE 5: Mother: Selected sub-skills of communication skills and skills at training the subject (all action routines) tervention (weeks nil to six), except for "feed the cat", results show a decline. Figure 6 results indicate that, except for "set the table", mother's communication skills increased from weeks nil to six. Sub-skills of mother's communication skills that increased at weeks nil to six (Figure 5) were "looks at subject", "physical contact" and "total utterances". Ignore responses were significantly less in weeks nil to six. These results indicate that for the subject and his mother a relationship existed between the subject's extent of experience and independence at action routines and the communication skills of the mother. It seemed that, as could be expected, increased independence of the subject at performing action routines, lessened the need for "supportive" communication from the mother and vice versa.

\section{CONCLUSIONS}

The PCI population is distinguished by it's heterogenicity and differences are the rule rather than the exception (Yoder \& Villarruel, 1988). A single case design was selected and no generalisations on the basis of these results, can be made. However, it appeared that overall increases in the results of the priority skills of both the mother and the subject could be ascribed to the implementation of communication intervention. A significant decrease in the results of three of the four priority skills after the withdrawal of intervention, strengthens the aforementioned presumption. When taking into account that the results of the PCI subject showed the highest increases overall, the most important conclusion points to the dynamic (vs static) nature of the subject's clinical features.

When comparing results at the different measurements, motivation seemed to be a key determinant of the features of the priority skills of the subject as well as the communication skills of the mother. Results indicated the necessity to target and provide positive reinforcement as well as consequent opportunities to perform skills together with a familiar person in the environment, in order to maintain the PCI subject's motivation and willingness regarding intervention aims.

The use of domestic action routines and the introduction and representation thereof by means of picture symbol task analysis charts, seem to have succeeded in the facilitation of interaction between the mother and the subject. Results which indicated that increased subject independence (at action routines) reduced the need for "supportive" communication from the mother, point to the need for flexibility regarding the selection and period that the

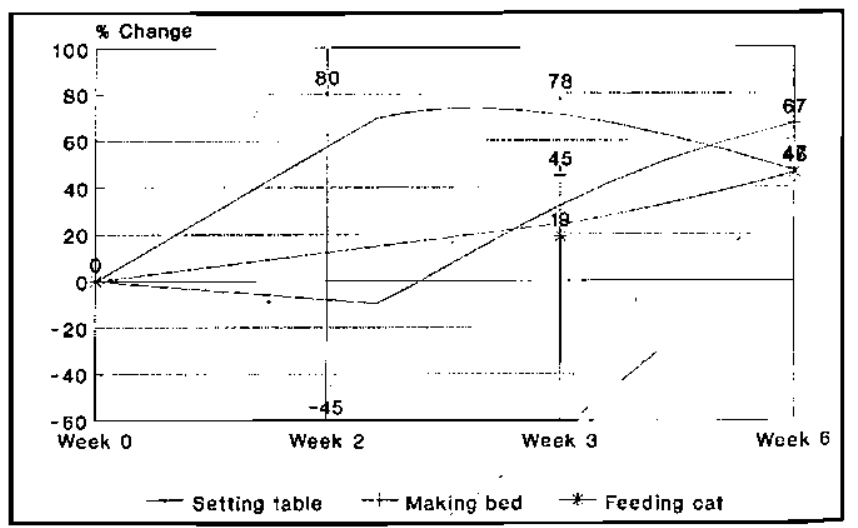

FIGURE 6: Mother: communication skills trends 
subject is expected to perform each action routine. Although in this study the action routine choice of the mother was used, mother's choices should be alternated with those of the subject. Additionally the possibilities of increasing the number of routines (alternating familiar and less familiar routines) or shortening the period of performance of each to less than a week per action routine, could be considered.

Due to the widely accepted acknowledgement of responsiveness as the facilitator of motivation and willingness to interact, increases in the mother's use of positive responses to the communication of the subject (possibly indicating a side-effect of positive reinforcement training), are viewed as significant. However, the slower tempo of change in the communication skills of the mother highlighted the need for a realistic and sensitive attitude towards social and historical aspects, daily stressors and general needs of the mother. Demands to change coping strategies and communication behaviours that were developed over years, necessitates a prolonged period of professional and social support. Additional sources of support could include the active involvement of other family members as well as societal support.

Results of communication intervention with the PCI subject indicated that these persons cannot be denied communication intervention on grounds of clinical features or psychometric classification alone. Poor progress during intervention does not indicate that the person is unable to benefit from intervention and therefore requires only physical care. To provide for the right of the PCI person to develop and maintain a quality of life equal to that of mainstream society, communication intervention must be aimed at the development of social integration through the facilitation of functional communication and independence skills. The PCI person forms one component of the environment in which he spends most of his time. For this reason primary caregiver skill development and sensitivity towards the environment cannot be overemphasised.

\section{REFERENCES}

Alant, E. \& Emmet, T. (1995). Breaking the silence: Communication and education for children with severe handicaps. Human Sciences Research Council, Pretoria.

Brown, L., Nisbet, J., Ford, A., Sweet, M., Shiraga, B, York, J. \& Loomis, R. (1983) The critical need for non-school instruction in educational programs for severely handicapped students. Journal of the association for the severely handicapped, 8 (3), 71-77.

Calculator, S.N. (1988a). Teaching functional skills in nonspeaking adults with mental retardation. In S.N. Calculator \& J.L. Bedrosian (eds). Communication assessment and intervention for adults with mental retardation. Boston, Mass.: College-Hill.

Calculator, S.N. (1988b). Promoting the acquisition and genera lisation of conversational skills by individuals with severe disabilities. Augmentative and Alternative Communication, 2(4), 94-103.

Carlson, F. (1985). PICSYMS categorical dictionary. Baggeboda Press, Rhode Island. St., Lawrence, K.S.

Conti-Ramsden, G. (1985). Mothers in dialogue with languageimpaired children. Topics in Language Disorders, 58-67.

Dunn, L.M. (1965). Peabody Picture Vocabulary Test. Circle Pines, Minn.: AGS.

Durant, M. (1990). Severe behaviour problems. New York, The Guilford Press.

Ehren, B.J. \& Lenz, B.K. (1989). Adolescents with language disorders: Special considerations in providing academically relevant language intervention. Seminars in Speech and Language, 3 (10), 192-203.
Eshilian, L., Haney, M. \& Falvey, M.A..(1989). Domestic skills. In M.A. Falvey (ed.). Community-based curriculum. Baltimore, Maryland: Brookes.

Girolametto, L.E., Greenberg, J. \& Manolson, H.A. (1986). Developing dialogue skills: The Hanen Early Language Parent Program. Seminars in Speech and Language 4(7), 367-379.

Gottlieb, M.L. (1989). The response of families to language disorders in the young child. Seminars in Speech and Language, $9(1), 47-53$.

Griffiths, R. (1984). Griffiths Mental Developmental Scales. Bucks: Association for Research in Infant and Child Development.

Grover, V. (1990). Psycho-educational aspects of mental handicap. In S. Lea \& D. Foster (eds). Perspectives on mental handicap in South Africa. Durban: Butterworth.

Haney, M. \& Falvey, M.A. (1989). Instructional strategies. In M.A. Falvey (ed). Community-based curriculum. Baltimore, Maryland: Brookes.

Haring, T.G. (1991). Social relationships. In L.H. Meyer, C.A. Peck \& L. Brown (eds). Critical issues in the lives of people with severe disabilities. Baltimore, Maryland: Brookes.

Helm, D.T. \& Kozloff, M.A. (1986). Research on parent training: shortcomings and remedies. Journal of Autism and Developmental Disorders, 16(1), 1-16.

Hollander, M. \& Wolfe, D.A (1973). Nonparametric statistical methods. New York: John Wiley \& Sons.

Johnson, J. \& Koegel, R.L. (1982). Behavioural assessment and curriculum development. In R.L. Koegel, A. Rincover \& A.L. Egel (eds). Educating and understanding autistic children. Calif.: College-Hill.

Kirchener, D.M. (1991). Using verbal scaffolding to facilitate conversational participation and language acquisition in children with pervasive developmental disorders. Journal of Childhood Communication Disorders, 14(1), 81-98.

Koördineringskomitee: Jaar van Gestremde Persone. (1987). Gestremdheid in die Republiek van Suid-Afrika: Behandeling. Vol. 3. Pretoria: Departement van Nasionale Gesondheid en Bevolkingsontwikkeling.

Lea, S. (1990). Psycho-social aspects of mental handicap. In S. Lea \& D. Foster (eds). Perspectives on mental handicap in South Africa. Durban: Butterworth.

Lund, N.J. (1986). Family events and relationships: Implications for language assessment and intervention. Seminars in Speech and Language $7(4), 415-429$.

Owens, R.E. \& Rogerson, B.S. (1988). Adults at the presymbolic level. In S.N. Calculator \& J.L. Bedrosian (eds). Communica. tion assessment and intervention for adults with mental retardation. Boston, Mass.: College-Hill.

Pansegrouw, I. (1994). Kommunikasie-intervensie by 'n kognitief erg gestremde adolessent met outistiese trekke. Ongepubliseerde M.Log verhandeling, Universiteit van Pretoria.

Rowland, C. \& Stremel-Campbell, K. (1987). Share and share alike; conventional gestures to emergent language for learners with sensory impairments. In L. Goetz, D. Guess \& K. StremelCampbell (eds). Innovative program design for individuals with dual sensory impairments. Baltimore, Maryland: Brookes.

Rustin, L. \& Kuhr, A. (1989). Social skills and the speech impaired. London: Taylor \& Francis.

Sailor, W. \& Guess, D. (1983). Severely handicapped students: an instructional design. Boston, Mass.: Houghton Mifflin.

Siegel-Causey, E. \& Downing, J.E. (1987). Nonsymbolic communication development: Theoretical concepts and educational strategies. In L. Goetz, D. Guess \& K. Stremel-Campbell (eds). Innovative program design for individuals with dual sensory impairments. Baltimore, Maryland: Brookes.

Singer, G.H.S. \& Irvin, L.K. (1991). Supporting families of persons with severe disabilities: Emerging findings, practices and questions. In L.H. Meyer, C.A. Peck, \& L. Brown (eds). Critical issues in the lives of people with severe disabilities. Baltimore, Maryland: Brookes.

Subcommittee on Mental Retardation. (1987a). DSM-III-R Classification: Axes 1 and 2 Categories and codes. In The American Psychiatric Association. Diagnostic and Statistical Manual of Mental Disorders ( ${ }^{\text {rd }}$ ed., rev.). Cambridge: The Press Syndicate, University of Cambridge.

Walker, M. (1972). Signs for Makaton. EARO.

Walker, M. (1985). Symbols for Makaton. EARO.

Wilson, A. (1981). Curriculum selection for the deaf-blind; Severely/profoundly handicapped. In S.R. Walsh \& R. Holzberg (eds). Understanding and educating the deaf-blind/severely 
and profoundly handicapped: an international perspective. Springfield, Illinois: Charles C. Thomas.

Yoder, D.E. \& Villarruel, F. (1988). Effective communication for the severely handicapped child. In N.J. Lass, L.V. McReynolds J.L. Northern \& D.E. Yoder (eds). Handbook of speech. language pathology and audiology. Philadelphia: B.C. Decker.

\section{APPENDDX 1: Grouping of sub-skills of priority skills of the subject and his mother}

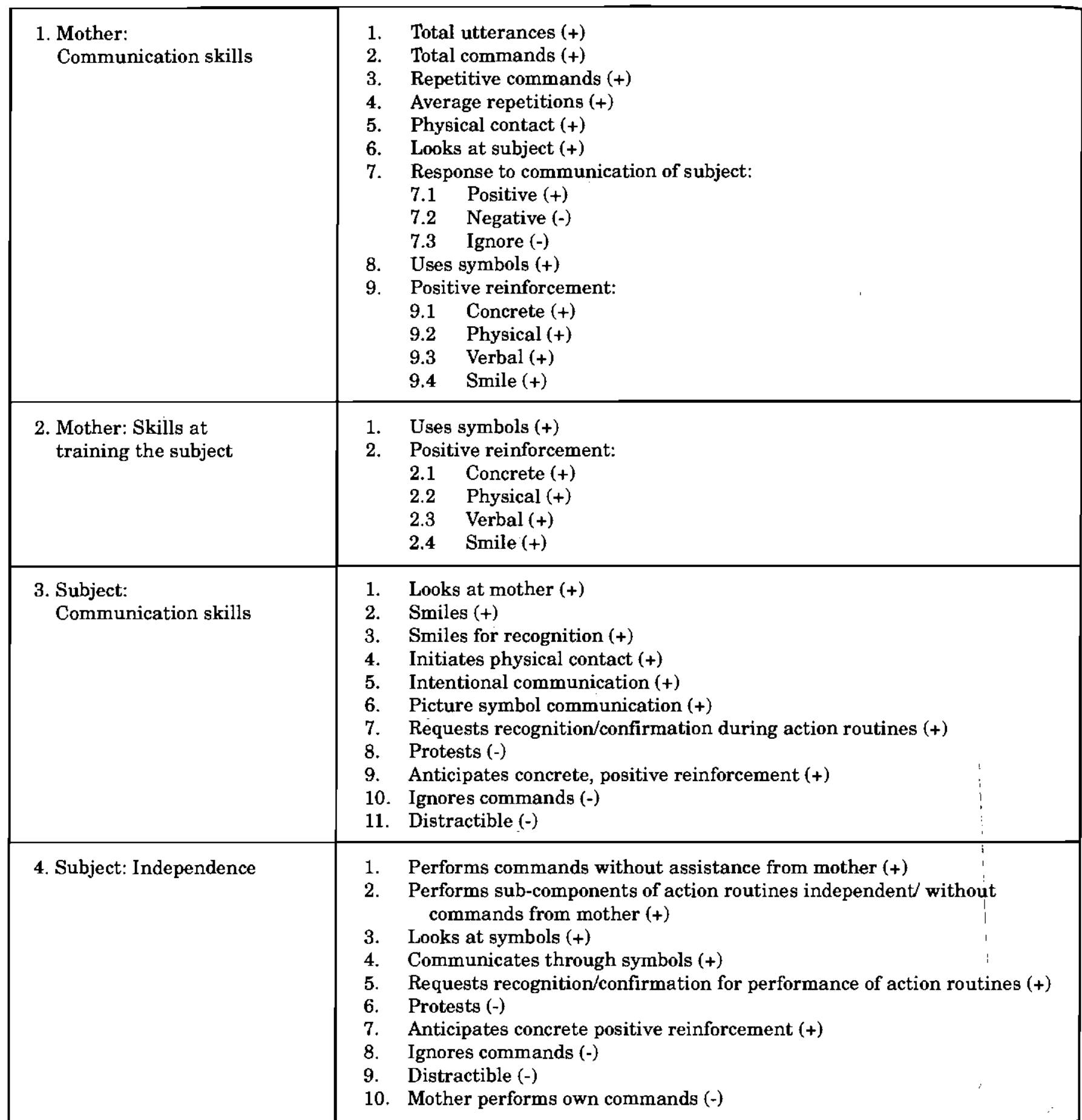


Communication Intervention in an Adolescent with Profound Cognitive Impairment and Aatistic Features

APPENDIX 2: Grid for recording and analysing data of the mother's skills at training the adolescent

\begin{tabular}{|c|c|c|c|c|c|c|c|c|c|c|c|c|c|c|}
\hline Task & \multicolumn{5}{|c|}{ Set the table } & \multicolumn{4}{|c|}{ Make the bed } & \multicolumn{3}{|c|}{ Feed the cat } & \multicolumn{2}{|c|}{ Average } \\
\hline Week & 0 & 1 & 2 & 3 & 6 & 0 & 2 & 3 & 6 & 0 & 3 & 6 & 3 & 6 \\
\hline Measurement & B & 1 & 2 & & 3 & $\mathrm{~B}$ & 1 & 2 & 3 & B & 1 & 2 & & \\
\hline \multirow[t]{2}{*}{ Time (min) } & 8 & 9 & 9 & & 10 & 2 & 12 & 4 & 2 & 4 & 9 & 5 & & \\
\hline & \multicolumn{5}{|c|}{ Mother } & \multicolumn{4}{|c|}{ Mother } & \multicolumn{3}{|c|}{ Mother } & & \\
\hline (*) 1 Use Symbols & 16 & 11 & 6 & & 5 & 12 & 5 & 7 & 2 & 11 & 7 & 3 & & \\
\hline 1.1 Count/Minute & 2 & 1.222 & 0.666 & & 0.5 & 6 & 0.416 & 1.75 & 1 & 2.75 & 0.777 & 0.6 & & \\
\hline $1.2 \%$ Change & 0 & -38.8 & -66.6 & -93 & -75 & 0 & -93.0 & -70.8 & -.83 .3 & 0 & -71.7 & -78.1 & -78 & -79 \\
\hline
\end{tabular}

2. Positive reinforcement

\begin{tabular}{|c|c|c|c|c|c|c|c|c|c|c|c|c|c|c|c|}
\hline 2.1 & Concrete & 0 & 7 & 5 & 6 & 0 & 5 & 5 & 5 & 0 & 9 & 7 & & & \\
\hline & Revised Count & 1 & 8.3 & 6.13 & 7.25 & 1 & 11 & 7 & 6 & 1 & 11.25 & 8.25 & & & \\
\hline & Count/Minute & 0.125 & 0.903 & 0.681 & 0.725 & 0.5 & 0.916 & 1.75 & 3 & 0.25 & 1.25 & 1.65 & 306 & 513 & \\
\hline & \% Change & 0 & 622.6 & 444.8 & 267 & 480 & 0 & 83.33 & 250 & 500 & 0 & 400 & 560 & & \\
\hline 2.2 & Physical & 1 & 2 & 3 & 2 & 1 & 1 & 2 & 0 & 1 & 1 & 0 & & & \\
\hline & Count $/$ minute & 0.125 & 0.222 & 0.333 & 0.2 & 0.5 & 0.083 & 05 & 0 & 0.25 & 0.111 & 0 & & & \\
\hline & $\%$ Change & 0 & 77.77 & 166.6 & 257 & 60 & 0 & -83.3 & 0 & -100 & 0 & -55.5 & -100 & 67 & -47 \\
\hline 2.3 & Verbal & 2 & 8 & 10 & 7 & 1 & 3 & 5 & 3 & 1 & 4 & 3 & & & \\
\hline & Count/Minute & 0.25 & 0.888 & 1.111 & 0.7 & 0.5 & 0.25 & 1.25 & 1.5 & 0.25 & 0.444 & 0.6 & & & \\
\hline & $\%$ Change & 0 & 255.5 & 344.4 & 433 & 180 & 0 & -50 & 150 & 200 & 0 & 77.77 & 140 & 220 & 173 \\
\hline 2.4 & Smile & 1 & 1 & 1 & 0 & 0 & 1 & 2 & 0 & 1 & 1 & 0 & & & \\
\hline & Revised Count & 1 & 7 & 4 & 1. & & & & & & & & & & \\
\hline & Count/Minute & 0.125 & 0.111 & 0.111 & 0 & 0.5 & 0.583 & 1 & 0.5 & 0.25 & 0.111 & 0 & & & \\
\hline & $\%$ Change & 0 & -11.1 & -11.1 & -11 & -100 & 0 & 16.66 & 100 & 0 & 0 & -55.5 & -100 & 11 & -66 \\
\hline Aver & rage & 0 & 181 & 176 & 171 & 109 & 0 & -25 & 86 & 103 & 0 & 59 & 84 & 105 & 99 \\
\hline
\end{tabular}


